\title{
Dificultad para conseguir un Acceso Vascular para hemodiálisis: Caso Clínico: 9 años en Hemodiálisis, 15 Accesos Vasculares
}

\author{
Laura Navarro Daudén, Ana Reula Carrillo, Eva Maa Martínez Olivares, Amparo Martínez Más,
} Rosa Ortells Corresa, Anna Martí Monros, Carme Moreno Aliaga

Enfermeras, Servicio Nefrología Hospital General Universitario de Valencia

\section{Introducción}

El acceso vascular (AV) constituye el "talón de Aquiles" del tratamiento con hemodiálisis (HD) ${ }^{1}$. Disponer de un AV no sólo es condición "sine qua non", si no que éste debe reunir algunos requisitos para conseguir una diálisis adecuada, tales como suministrar un flujo de sangre suficiente, no plantear problemas de utilización a largo plazo y tener una baja tasa de complicaciones ${ }^{2}$. La fístula arteriovenosa interna (FAVI) es el AV idóneo, siendo preferible la FAVI con vena autóloga al injerto de politetrafluoroetileno (PTFE), por los mejores resultados de aquella a largo plazo. Pero cuando dicho acceso no puede ser realizado, 0 bien no tiene los resultados esperados, hay que recurrir a la inserción de un catéter venoso central, siendo la mejor opción el uso de catéteres tunelizados. Con el aumento de la prevalencia de pacientes añosos y diabéticos en la población de pacientes en hemodiálisis, actualmente el uso de este tipo de catéteres es mucho más frecuente ${ }^{3}$. Todos tenemos la experiencia de que en ocasiones resulta muy difícil conseguir un acceso vascular adecuado.

$$
\begin{gathered}
\text { Correspondencia: } \\
\text { Carme Moreno Aliaga } \\
\text { Servicio de Nefrología HGUV } \\
\text { Avd. Tres Cruces N² } \\
46010, \text { Valencia } \\
\text { e-mail: carmemorenoaliaga@gmail.com }
\end{gathered}
$$

Presentamos un caso clínico en el que destaca la lucha tanto del paciente como de los profesionales por conseguir y mantener el $\mathrm{AV}$, mediante el trabajo en equipo y la empatía paciente-personal asistencial. Nos parece importante mencionar el impacto tanto para el paciente como para la familia de los ingresos y las diferentes asistencias hospitalarias causadas para conseguir el $\mathrm{AV}$, puesto que nuestra unidad está situada a $97 \mathrm{~km}$ del domicilio.

\section{Caso clínico}

Varón de 72 años en programa de HD desde diciembre2002, por insuficiencia renal secundaria a nefrectomía bilateral por neoplasia renal (1999 y 2002).

Antecedentes de hipertensión arterial, apendicectomía, colecistectomía y herniorrafia inguinal derecha. Esplenectomía por lesión del bazo durante la nefrectomía derecha (2002). Trombosis venosa en el miembro inferior derecho condicionada por la canulación de la femoral (catéter de diálisis). Colitis isquémica, poliposis de colon y hemorragia digestiva baja en 2007. En diciembre-08 nuevo episodio de hemorragia digestiva baja por angiodisplasia. Diagnosticado en 2009 de estenosis valvular aórtica moderada-severa.

\section{Historia del acceso vascular:}

- Comenzó tratamiento en diciembre-02 mediante un catéter femoral derecho. Se retiró en febrero-03 (trombosis venosa). 
- En enero-03 se practicó una FAVI húmero-cefálica izquierda. Se comenzó a utilizar a las 4 semanas. Desarrolló una dilatación aneurismática, presentando una trombosis parcial (diciembre-03), que permitía su uso en unipunción.

- En diciembre-03 se practicó una FAVI húmerobasílica derecha que no llegó a funcionar.

- El mismo mes se implantó un injerto de PTFE húmero-axilar derecho, con trombosis a las 24 horas. Se le tuvo que extirpar por infección en enero-04.

- Por disfunción de la fístula izquierda, en enero-04 se implantó un un catéter tunelizado en la yugular interna izquierda. Se utilizó como AV hasta julio-04, retirándose por infección refractaria a la antibioterapia.

- El 22-7-04 se produjo un intento fallido de canalizar la yugular interna derecha, colocándose un catéter en la vena femoral derecha: se retiró en sep-04, al disponer de una FAVI funcionante.

- Nuevamente, el 23-7-04 se intentó canalizar sin éxito tanto la yugular interna derecha como la izquierda.

- El 4-8-04 se implantó una prótesis de PTFE entre la arteria y la vena femoral izquierda. Se utilizó desde septiembre hasta el 22-10-04 (trombosis no recuperable).

- El mismo día 22-10-04 se implantó un catéter tunelizado en la yugular interna derecha:

- En octubre-05 presentó un episodio de bacteriemia por E. Coli, resuelto con antibioterapia.

- Posteriormente el catéter dio problemas de flujo insuficiente, precisando con frecuencia tratamiento fibrinolítico tanto local como sistémico.

- Por este motivo, en noviembre-06 se indicó anticoagulación con acenocumarol (Sintrom ${ }^{\circledR}$ ), con leve mejoría funcional.

- En febrero-07 sufrió un episodio de hemorragia digestiva baja, por colitis isquémica y pólipos en colon y condicionada por el tratamiento anticoagulante.
- Después de retirar el acenocumarol el catéter dejó de dar flujo.

- El 22-2-07 se intentó sustituir el catéter a través del mismo trayecto venoso, siendo imposible la introducción del nuevo catéter por trombosis completa de la cava superior.

- El mismo día 22-2-07 se colocó un catéter temporal en la vena femoral izquierda. Se retiró el 2-3-07 al disponer de un catéter central funcionante.

- El 28-2-07 se colocó un catéter tunelizado tipo SplitCath directamente en aurícula derecha, mediante mini-toracotomía anterior derecha.

- Desde la primera sesión de diálisis presentaba una mínima fuga de sangre, a través de la unión del catéter con las extensiones de conexión. No fue impedimento para seguir utilizándolo.

- Hospitalización en octubre-07 por infección del catéter, resuelta con antibioterapia.

- En noviembre-07 aumentó significativamente la fuga de sangre, solucionándose con sellado de silicona estéril y colocando una funda de PTFE alrededor del punto de fuga.

- En marzo-09 volvió a presentar la fuga de sangre, resuelto con el mismo procedimiento de sellado $y$ funda de PTFE.

- El 30-11-09 volvió a fugar, fracasando un nuevo intento de sellado.

- El 22-3-09 precisó de la inserción de un catéter temporal en femoral derecha durante unos días.

- El 17-12-09 se procedió a un nuevo recambio transtorácico por toracotomía, colocándose otro catéter tipo Split-Cath.

- Como complicación, presentó un shock cardiogénico post-cirugía, siendo diagnosticado entonces de una estenosis valvular aórtica moderada-severa.

- El catéter daba un flujo inadecuado, demostrándose que los extremos distales estaban ubicados en la vena suprahepática. 
- El 25-3-10 se procedió a recolocarlo en hemodinámica, quedando situados los extremos distales del catéter en cava inferior.

- El 24-9-10, nuevamente por disfunción del catéter, se volvió a recolocarlo en hemodinámica, quedando los extremos distales alojados en la aurícula derecha.

- El 22-3-10 precisó de la inserción de un catéter temporal en femoral derecha durante unos días.

Desde el último episodio del día 24-9-10 y hasta la fecha de hoy (10-02-2012), el paciente se dializa en su centro de diálisis por el catéter transtorácico, sin incidencias y con adecuada función del catéter.

\section{Discusión}

Debido a la dificultad que se transformo en imposibilidad de obtener un acceso vascular de los que pueden ser considerados como "convencionales" incluido los catéteres tunelizados, nos vimos obligados a plantear otro abordaje. Teníamos la experiencia de un paciente portador de catéter en vena cava inferior, bienfuncionante, por lo que decidimos, después de búsqueda bibliográfica exhaustiva el implante de un catéter translumbar.

Como hemos comentado, el paciente en la actualidad realiza sus sesiones de hemodiálisis por vía catéter translumbar sin ningún problema y un funcionamiento perfecto, siempre siguiendo las normas de asepsia que cualquier catéter venoso central requiere.

\section{Conclusión}

En la actualidad ya contamos con dos pacientes mas portadores de catéteres translumbares en pacientes en los que los otros recursos para obtener un Acceso Vascular se habían agotado, en la actualidad, varios meses después de su implante, ambos siguen con el catéter funcionante y sin ningún problema digno de mención.

Para finalizar queremos añadir que las cargas de trabajo enfermero son las mismas que con los catéteres tunelizados de uso habitual en las Unidades de Hemodiálisis.

Recibido: 10 Febrero 2012

Revisado: 10 Marzo 2012

Modificado: 20 Julio 2012

Aceptado: 10 Agosto 2012

\section{Bibliografía}

1. J.R. Polo, J.M. López. Accesos vasculares para hemodiálisis. En: L.Hernando Avendaño. Nefrología Clínica Ed. Panamericana 2008, (19) p.889-904.

2. John T. Daurgidas. Catéter venoso central para hemodiálisis. En: Manual de diálisis cap 6, p. 86103.

3. J.A. Rodríguez Hernández et al. Guías SEN. Guías de acceso vascular en hemodiálisis. Nefrología. V 25, supl 12005.

4. I. Crehuet, S. Mendieta, P. Méndez, R. González. Catéter trasnlumbar en vena cava inferior, última opción de acceso vascular para hemodiálisis.

Rev Soc Esp Enferm Nefrol, VII N³ 2008, p. 238241 